\title{
Lusioersily
}

\section{Reflections on "YouTestTube.com": An Online Video-Sharing Platform To Engage Students with Chemistry Laboratory Classes}

McClean, S., McCartan, K., Meskin, S., Gorges, B., \& Hagan, W. (2016). Reflections on "YouTestTube.com": An Online Video-Sharing Platform To Engage Students with Chemistry Laboratory Classes. JOURNAL OF CHEMICAL EDUCATION, 93(11), 1863-1870. https://doi.org/10.1021/acs.jchemed.6b00045

Link to publication record in Ulster University Research Portal

Published in:

JOURNAL OF CHEMICAL EDUCATION

Publication Status:

Published online: 02/09/2016

DOI:

10.1021/acs.jchemed.6b00045

Document Version

Author Accepted version

\section{General rights}

Copyright for the publications made accessible via Ulster University's Research Portal is retained by the author(s) and / or other copyright owners and it is a condition of accessing these publications that users recognise and abide by the legal requirements associated with these rights.

\section{Take down policy}

The Research Portal is Ulster University's institutional repository that provides access to Ulster's research outputs. Every effort has been made to ensure that content in the Research Portal does not infringe any person's rights, or applicable UK laws. If you discover content in the Research Portal that you believe breaches copyright or violates any law, please contact pure-support@ulster.ac.uk. 


\section{Reflections on 'YouTestTube.com' an online video sharing platform to engage students with chemistry laboratory classes}

Stephen McClean ${ }^{*}$, Kenneth G. McCartan ${ }^{2}$, Sheryl Meskin ${ }^{3}$, Beronia Gorges ${ }^{1}$ and W. Paul

$5 \quad$ Hagan $^{4 \frac{4}{*}}$

1. School of Biomedical Sciences, University of Ulster, Coleraine, Co Londonderry, BT52 1SA

2. ICT Customer Services, University of Ulster, Jordanstown, Newtownabbey, Co. Antrim, BT37 OQB

10 3. UK Centre for Bioscience, the Higher Education Academy, Room 9.15, Worsley Building, University of Leeds, Leeds, LS2 9JT. Current address, Lifelong Learning Centre, Level 11, Marjorie and Arnold Ziff Building, University of Leeds, Leeds, LS2 9JT

4. School of Pharmacy and Pharmaceutical Sciences, University of Ulster, Coleraine, Co Londonderry BT52 1SA

15 ‡ Deceased: $1^{\text {st }}$ June 2016 .

\section{ABSTRACT}

This paper describes the construction and development of YouTestTube.com, a YouTube clone website to facilitate video sharing, social networking, and reflection of chemistry laboratory classes for year one students within the School of Biomedical Sciences at Ulster University. The practice was first introduced in the 2008/09 academic year and has developed until the present time. We reflect on our findings with regard to the production and sharing of short student-generated video documentaries on laboratory experiments, and attendant social networking. We found that students enjoyed the process of viewing, rating and commenting upon colleagues' videos but that social networking did not happen spontaneously or organically. Students did find that learning and networking happened effectively when working in small groups to produce the final version of the video. The use of some of the videos as peer-generated learning 
objects was reported useful in helping engage year one, semester one students in their early days in tertiary education.

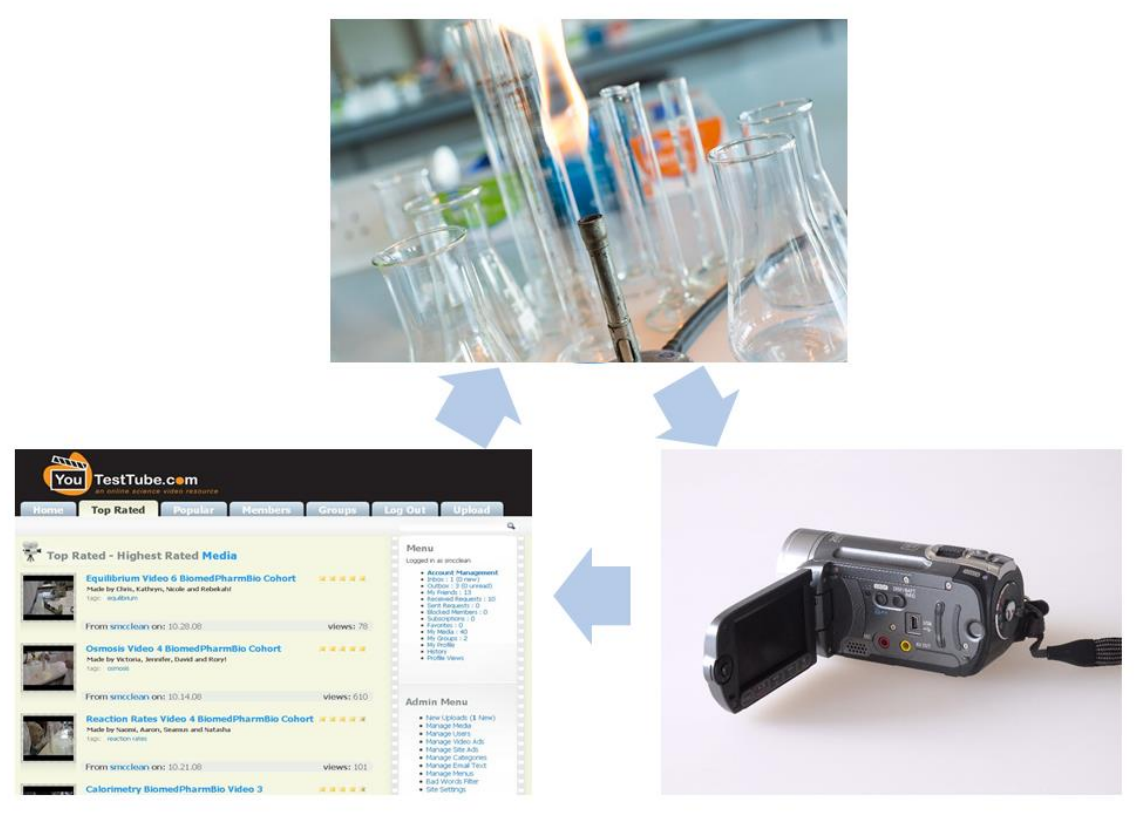

AS

\section{KEYWORDS}

First-Year Undergraduate / General; Laboratory Instruction; Computer-Based Learning

\section{INTRODUCTION}

The use of video in the educational context continues apace ${ }^{1}$. Professionally produced video is commonly used as an aid to teach specific topics and is exemplified in such websites as the Journal of Visualized Experiments ${ }^{2}$ and DNATube ${ }^{3}$.

In a study conducted by Choi and Johnson ${ }^{4}$ the authors found significant difference in learners' motivation in terms of attention between video-based instruction and traditional text-based instruction and found video-delivered material much more memorable. As implied in constructivist theories of learning which contend that 
learners generate knowledge and understanding from interactions between their experiences and facts presented on a particular topic, technology such as video provides opportunities for students to engage in productive learning activities ${ }^{5}$. Hilton studied two groups of students conducting a science investigation where one group recorded their findings using a written text (posters) and the other produced videos. Quantitative results revealed greater learning gains for the video producers ${ }^{6}$.

Other studies have described how video may help prompt reflection of teaching practice $^{7}$ while a project on the role of live video capture on the development of student communication skills noted that the process contributed to self and peer reflection ${ }^{8}$. Berk has reviewed the use of multimedia teaching with video clips and argues that the literature to date reveals that auditory/verbal and visual/pictorial stimuli increase students' memory, comprehension, and deeper learning of a topic than when either stimulus is used by itself 9 .

While video generated by professionals, academics or students is often hosted on the closed environment of the institutional virtual learning environment (VLE), the phenomenon of video sharing on sites such as YouTube and Vimeo offers significant potential for educational purposes ${ }^{9,10}$. However, cultural differences and the roles of teachers and learners often contribute to a variance in the use of YouTube in different learning contexts ${ }^{11}$.

Smith has shown that video sites such as YouTube can be used to deliver educational resources to students, but may also facilitate students as producers in uploading their own video and in turn helping foster an online chemistry community ${ }^{12}$. A similar approach has been described by Ryan who used YouTube to host studentgenerated video and discovered that overall the process engendered a high level of engagement from the student cohort ${ }^{13}$. Willmott has used student-generated video in 
the teaching of bioethics and contends that such an approach provides a means of authentic assessment where learning is assessed through "real world" tasks ${ }^{14}$.

While YouTube and Vimeo are among the most popular video sharing sites, solutions exist which allow for the creation of video sharing websites or "YouTube clone" sites which have all the benefits of a video sharing platform, but in a manner where the site is hosted locally and authentication of students enrolling can take place in a controlled manner. Software solutions include Vidiscript ${ }^{15}$ and phpMotion ${ }^{16}$, or Kaltura ${ }^{17}$ which is available as a building block for the VLE platform Blackboard.

\section{CONTEXT OF THE CURRENT PRACTICE}

Students undertaking degrees in the biosciences at Ulster University must have a fundamental understanding of chemistry as this is foundational to other applied topics in subjects such as biomedical science, dietetics, food \& nutrition, human nutrition and biology. Students entering such courses sometimes have little chemistry background and for some the teaching laboratory can be a daunting experience. In these circumstances the constructivist argument for learning has weight as students incrementally and experientially build upon theory delivered in lectures combined with practical application in the laboratory, within a twelve week period. Instructional video is often used to complement traditional lecture or tutorial material, and to explain practical protocols in the laboratory context.

We have introduced a number of measures to support students in their learning of chemistry in higher education, particularly in their first year of study ${ }^{18}$. Further reflection on our practice led to a deeper consideration of year one chemistry practical classes. We saw these as an opportunity to enhance inclusivity and contribute to students building friendship networks and subsequently peer-support during semester 
one, particularly in a year one class with an average enrolment of around 150. This development was timely in the light of discipline-specific studies looking particularly at the delivery of laboratory classes in higher education, ${ }^{19-21}$ and especially when some students have rated practical experiences as poor and lacking relevance ${ }^{22}$. We saw video production and sharing as a means to increase the learning value of timeintensive resource-expensive laboratory teaching sessions while contributing to the development of students' digital skills.

The specific evaluative questions for the YouTestTube project were;

1. Does student-generated video production and sharing enhance opportunities for active learning during and after practical classes, thereby prompting better engagement with practical work and how it relates to lectures and fits with the course content as a whole?

2. Can an in-house YouTube-clone website facilitate video sharing and social networking thereby helping to engender friendship networks in a large ( $n \sim 150)$ first year group with a broad range of educational backgrounds?

3. Does such an approach provide students with opportunities to develop digital video production skills, and produce reusable learning objects that could benefit their peers or other groups of students?

\section{DESCRIPTION OF THE PROJECT}

The project was run in the semester one year one module BMS105 Chemistry in Practice taken by students enrolled on bioscience courses within the School of Biomedical Sciences at Ulster University. The average enrolment for this module in the years 2008/09 to $2014 / 15$ was 149 . 
Creation of the YouTestTube Site

The project was first piloted in the 2008/09 academic year and has operated in every year since that time. A number of incremental adjustments have been made to the organization of the project, and the most current iteration is described here. An inhouse video sharing website, YouTestTube.com was built using open source Vidiscript software ${ }^{15}$. This platform allows for the uploading and sharing of videos in a manner similar to the internet video-sharing website YouTube ${ }^{23}$. The expertise of a computing officer was required for the configuration of the website initially on an in-house webserver, but the general administration of the site may be achieved using web forms and intuitive commands to manage media and users. Staff time is required to ensure that students are enrolled correctly on the site, and to allocate cameras to groups of students during the practical session itself; however neither task has proved onerous. A screenshot of the website is shown in Figure 1. 


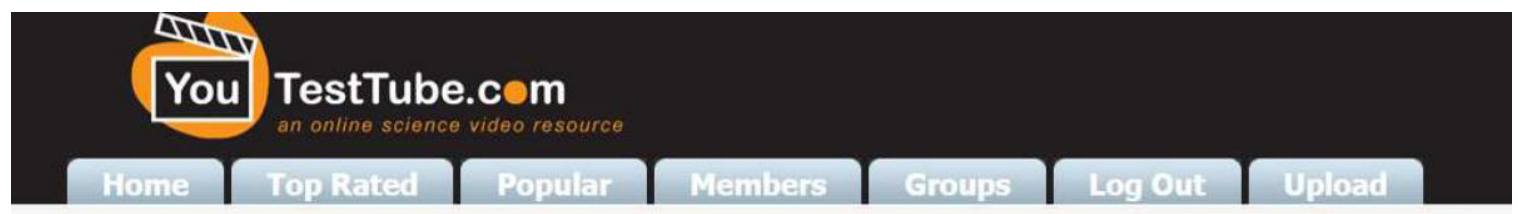

Q

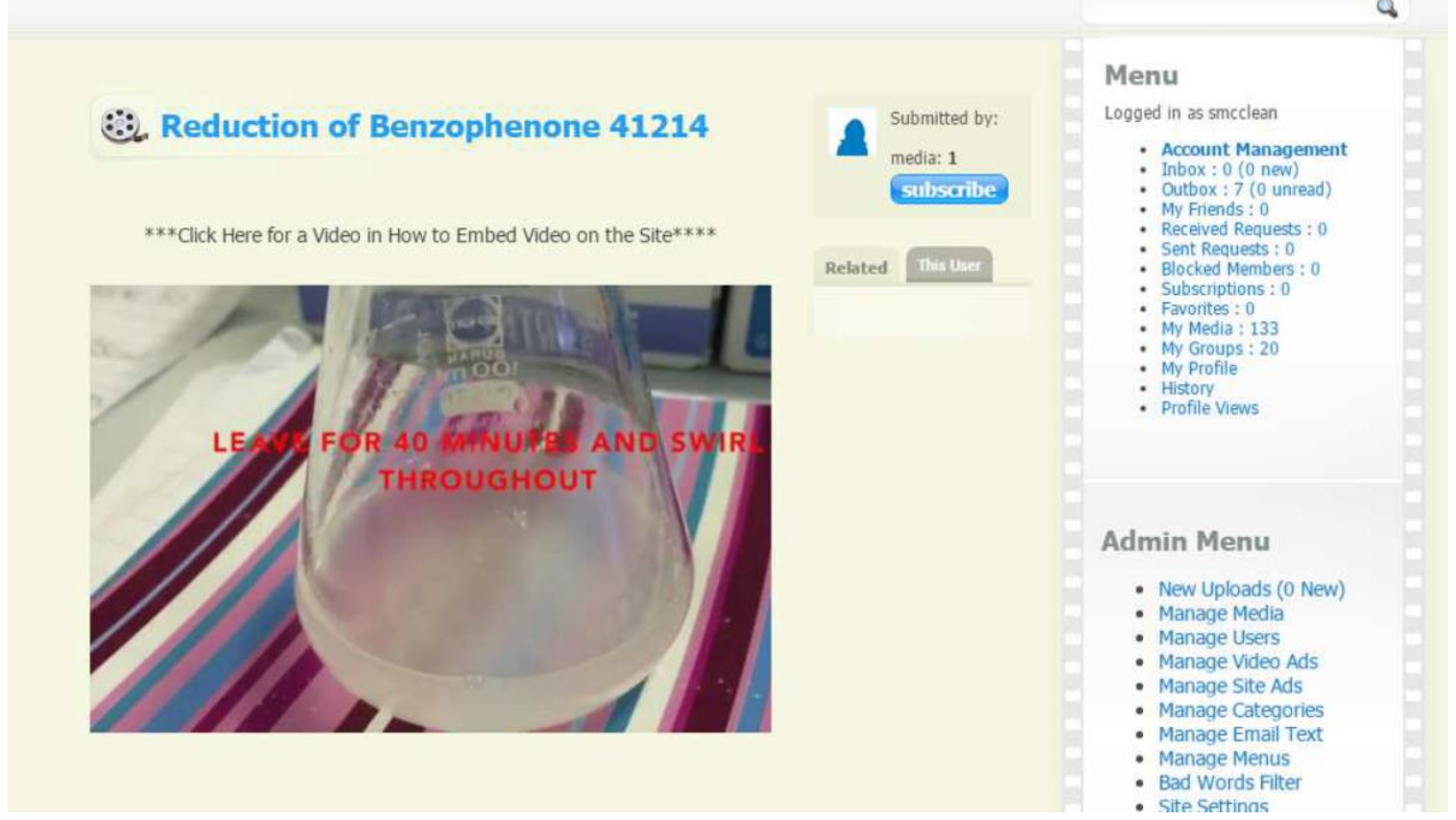

Figure 1. Screenshot of the YouTestTube.com website. Student names have been removed to preserve anonymity.

\section{Student-Facing Activity}

At the start of semester students are introduced to the YouTestTube.com website and briefed on the task they will complete. A bank of "frequently asked questions" (FAQs) has accumulated over the years of the project and serves to provide clarity to students on the task to be performed. This list is provided as associated content for others interested in replicating the project in their own practice. Students register on the site with their Ulster University email address (for authentication purposes) and then join the chemistry practical group before they can view or submit videos. This process provides the group with the reassurance that only the students on the module and the module teaching team have access to the site and the media from 
their group in particular. The site is not publicly available other users. Three video cameras were available and were provided to three groups of students (each comprising three or four students) for each practical session. However, students were also encouraged to use their own equipment (cameras, mobile phones) to capture video, if they wished to do so and this was the preferred option in the majority of cases. Access to recording equipment was rarely an issue. The video was recorded during the laboratory session, paying attention to key observations from the experiments conducted, difficulties encountered, and conclusions drawn. Students were also asked to reflect on how the skills gained in the underlying aspects of chemistry fit into their overall program of study. To assist with this, a series of "reflective prompts" of things that should be covered in the video was provided to students ${ }^{23}$ and is presented below. This list of prompts is also included in the supporting information.

- What is this practical all about?

- What skills have I learned?

- How does this practical tie-in with the lectures?

- How will this be important for other parts of my course?

- What parts of the practical were difficult?

- What was most/least enjoyable about the practical?

- If someone else was about to conduct this experiment again; what advice (about the practical) would I give them?

In the academic years $2008 / 09$ to $2011 / 12$ the footage captured by students was uploaded directly to YouTestTube by the academic in charge of the practical 
session. This process was cumbersome and time consuming for the staff member and gave students little ownership in the editing of their video. From the 2012/13 academic year onwards students leave the laboratory with their captured footage or images and then spend some time as a small team producing and uploading the final video to the YouTestTube.com site. This gives students the opportunity to take ownership of their video submission and clearly defines their role as producers of edited digital content. In fact, students were encouraged to be creative in how they presented the final video and so no specific format was suggested to them, though exemplars from previous years were shown the group. This provided reassurance to some students who felt uncomfortable about appearing on camera and instead opted to produce an animated video or use still pictures overlaid with captions or verbal narration.

To support students in the production of a digital video, a tutorial was offered to the module group explaining the basics of using the video editing package Windows Live Movie Maker24, which was available on all student computers at Ulster University. Further instruction was provided on uploading the final video to the YouTestTube site. Some students chose to post the video to their own YouTube channel initially and then embed it into the YouTestTube site; instruction was provided on how to do this.

\section{Assessment of Student Activity}

Students were asked to view, rate and comment on their colleagues' videos as they appeared on the YouTestTube site during the course of the module. Prizes were also given at the end of semester for the most highly rated and most popular videos, to emphasise the "fun" element of the project.

At the end of each semester an online questionnaire was used to determine each student's individual level of engagement with the YouTestTube site, and to ensure that 
they had rated, commented on, and "made friends" using the social networking functions of the site.

The video-making exercise comprised one component of the overall assessment regime for the module. Students were also assessed on written accounts of practical work (five laboratory sessions in all), a practical skills examination, and summative class tests. Each of the videos was assessed by an academic member of staff against a basic rubric for production, accuracy, communication and overall impact. With the agreement of the student group both the mark and feedback were communicated in the comments section for the video submission (though this might not be appropriate in all jurisdictions and is a practice that we will keep under review for the future). The same mark was provided to all group members and along with the individual mark for engagement in the process (as highlighted above), contributed to the overall coursework assessment for the module.

\section{Reusable Learning Objects}

Selected student-generated videos are now offered to cohorts in subsequent years thereby providing a preview of the practical to be undertaken. The videos are selected by academic staff based on their quality and clarity in presenting a comprehensive overview of the practical to be undertaken. This gives opportunity for new students to gain some familiarity with the practical they will conduct and the actual apparatus that will be used.

\section{EVALUATION OF THE PROJECT}

Since its inception the format of the activity underwent incremental change, and in the $2012 / 13$ academic year, students $(n=154)$ were given the opportunity to edit their own material before uploading the final submission to the YouTestTube site. This 
process continues to the present time. Evaluation of student uptake and perception of the project in its current format, was undertaken using the following approach:

215 1. A questionnaire at the start of the semester to gauge students' prior use of video and their initial impressions of the project

2. A questionnaire administered towards the end of semester to evaluate student opinion on the use of video in practical classes. Students were advised that the surveys were anonymous and that their participation was voluntary.

3. Interviews with three students on their experiences of being involved in the YouTestTube activity after the module had ended.

In general our evaluation is around students' perceptions of the YouTestTube project and their own reported learning gains as a result of being involved in it.

\section{Ethical Approval}

225 The School of Biomedical Sciences Ethics Filter Committee at Ulster University classified this project as service evaluation and therefore ethical approval was not required.

\section{Pre-Project Questionnaire}

A total of 128 students of the 154 enrolled on the module took part in the preproject questionnaire. The questions were designed to gauge students' previous use of video in learning and their initial impression of the task they would undertake. In all 115 out of 127 students (91\% - one student did not respond) had never made a video as part of their learning experience prior to coming to university. While $86 \%$ of students were familiar with using a video camera some $66 \%$ were not familiar with editing video. However, $70 \%$ had uploaded video to popular social media and networking sites such as YouTube and Facebook. This confirmed that in the main, students would be able to 
cope with the technical demands of the project. When informed about the proposed video activity, 99/128 students (77\%) said they were nervous or apprehensive about making a video and sharing it with the group. It transpired in talking to students that there was reluctance on the part of some to appear in the video, though this concern was remedied by reassurance that a "personal appearance" was not a requirement.

With regard to learning $112 / 128(88 \%)$ students agreed that video is a useful tool for learning about the practical techniques in science subjects, but a slightly lower number (101/128) 79\% thought that watching videos made by their peers would be an effective means of learning. A high proportion (87\%) agreed that making a video would help them think more about the processes of the experiment and the associated theory. Around $71 \%$ of students felt that viewing, rating and commenting on videos would be an effective means of getting to know people on the module.

\section{Post-Project Questionnaire}

A smaller number of students $(n=98)$ took part in the post-activity questionnaire. In general, a high percentage of students were satisfied with the technical aspects of the YouTestTube project in their studies (see Figure 2). Students felt confident in using the video equipment and also the laboratory apparatus used as part of the practical. 


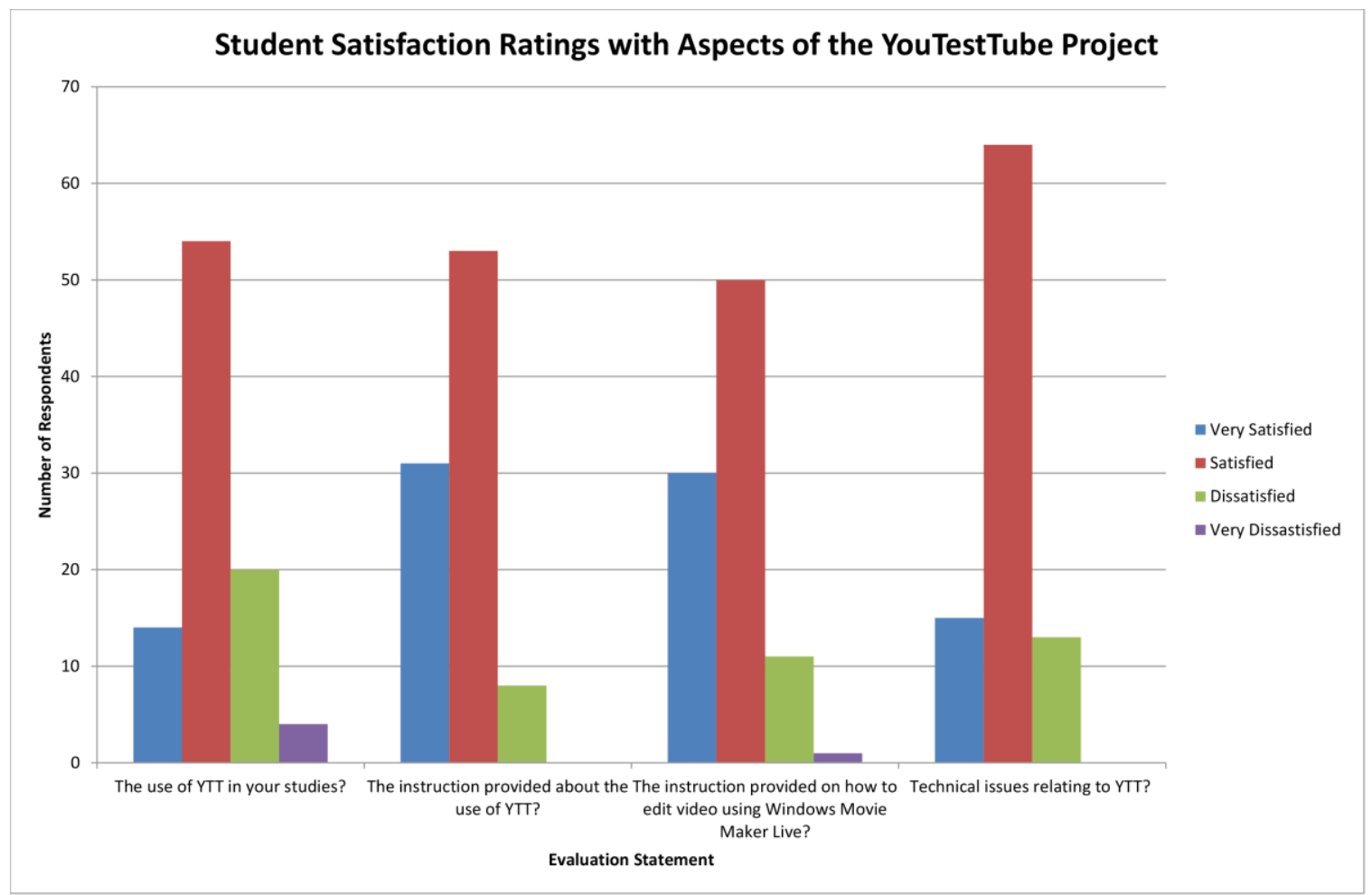

Figure 2. "Student satisfaction" responses to technical aspects of the YouTestTube project. Total number of respondents = 98; 2012/13 academic year.

A majority of students (62\%) enjoyed the process of creating and editing video and felt they had developed new skills as a result (see Figure 3). A majority (72\%) also agreed that participation in the video project helped them make connections between the theoretical aspects of the course and the practical work in the laboratory context. Fewer (58\%) students agreed that the project helped them to learn from the comments of others. This is not surprising as the majority of comments posted by students tended to be social in nature and did not discuss specifically the scientific content of the video. Some students commented on the technical or production aspects of the video, but rarely the scientific content was challenged or discussed. 


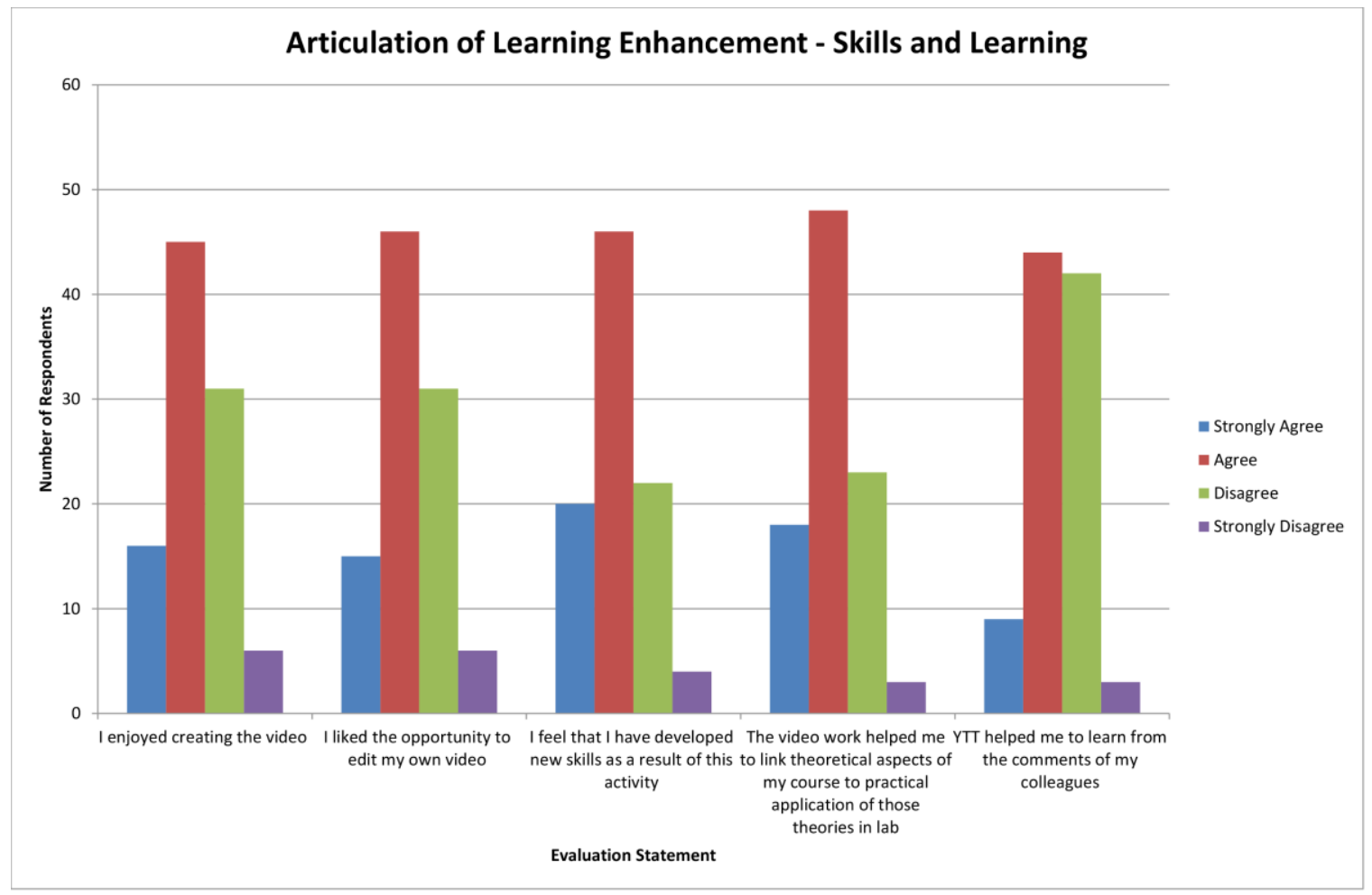

Figure 3. Student responses relating to gains with regard to skills and learning on the YouTestTube.com project. Total number of respondents $=98$ 2012/13 academic year.

Learning gains are outlined in the initial part of Figure 4 which shows that the project was successful in helping students: 1) reflect on aspects of their course, 2) improve understanding of course material and 3) increase confidence in putting forward views regarding student work (see Figure 5), albeit in a social context as highlighted above. Students were less convinced that the process helped them make friends or get to know others. They were also less convinced that discussion about learning materials between students was enhanced due to participation with YouTestTube.com site (see Figure 5). 


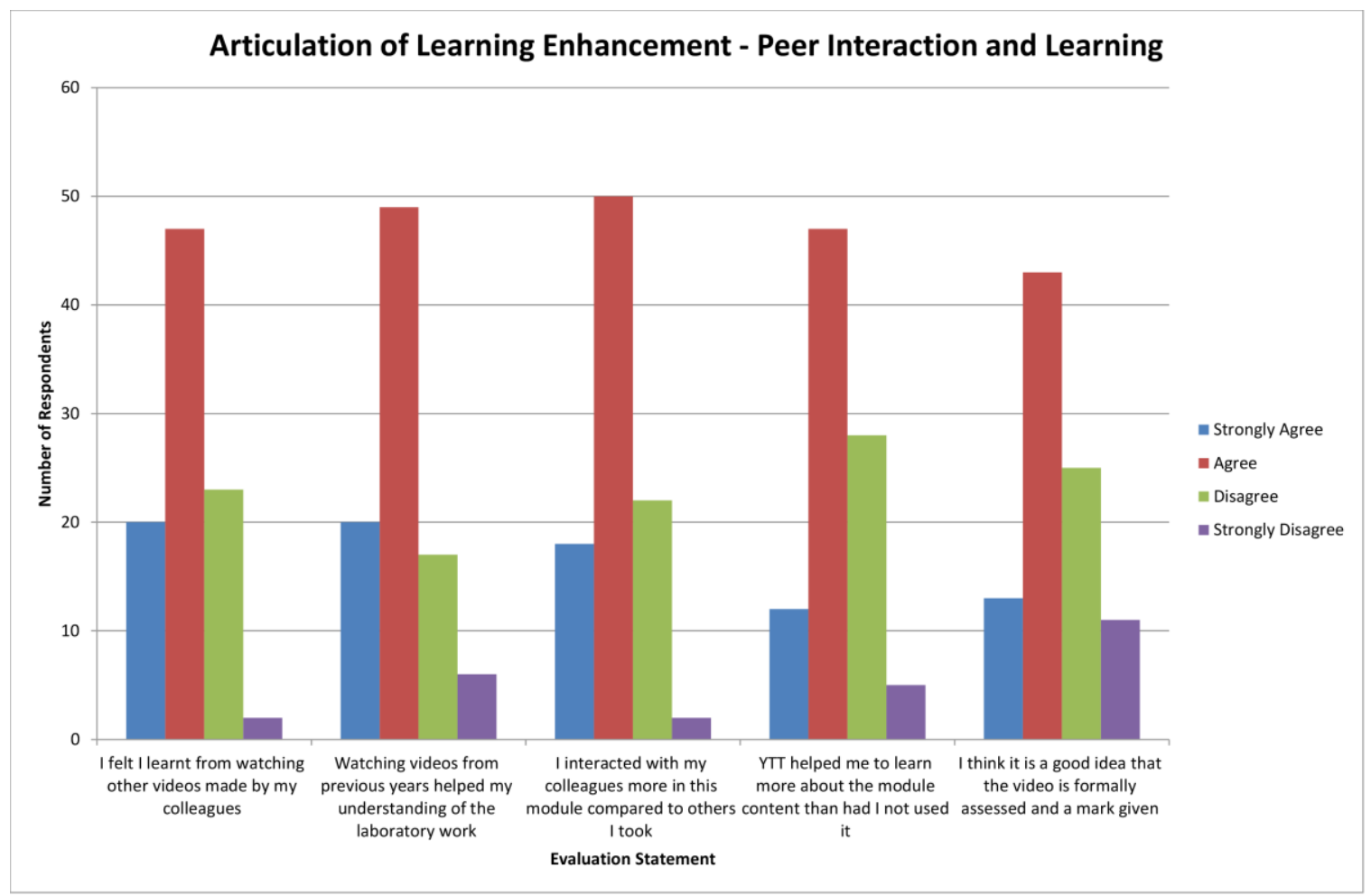

Figure 4. Student responses to peer interaction and learning aspects of the YouTestTube.com project. Total number of respondents $=98 ; 2012 / 13$ academic year.

Figure 4 also demonstrates that watching videos made by their colleagues in the same or previous year groups benefited students in learning about laboratory techniques. Students claim that they interacted more on this module compared to other modules taken in the same semester and that the use of YouTestTube helped them learn more about the module content.

The results presented here show that while a majority of students comment positively on YouTestTube, even thinking it a good idea that the activity is assessed (Figure 4), there is a significant number of students who do not find the activity useful and only $41 \%$ of students said they would like to use YouTestTube again. Some students felt that making a video was not relevant to a science degree, and in response 
to this we have sought to articulate the benefits of such a venture in enhancing digital and communication skills.

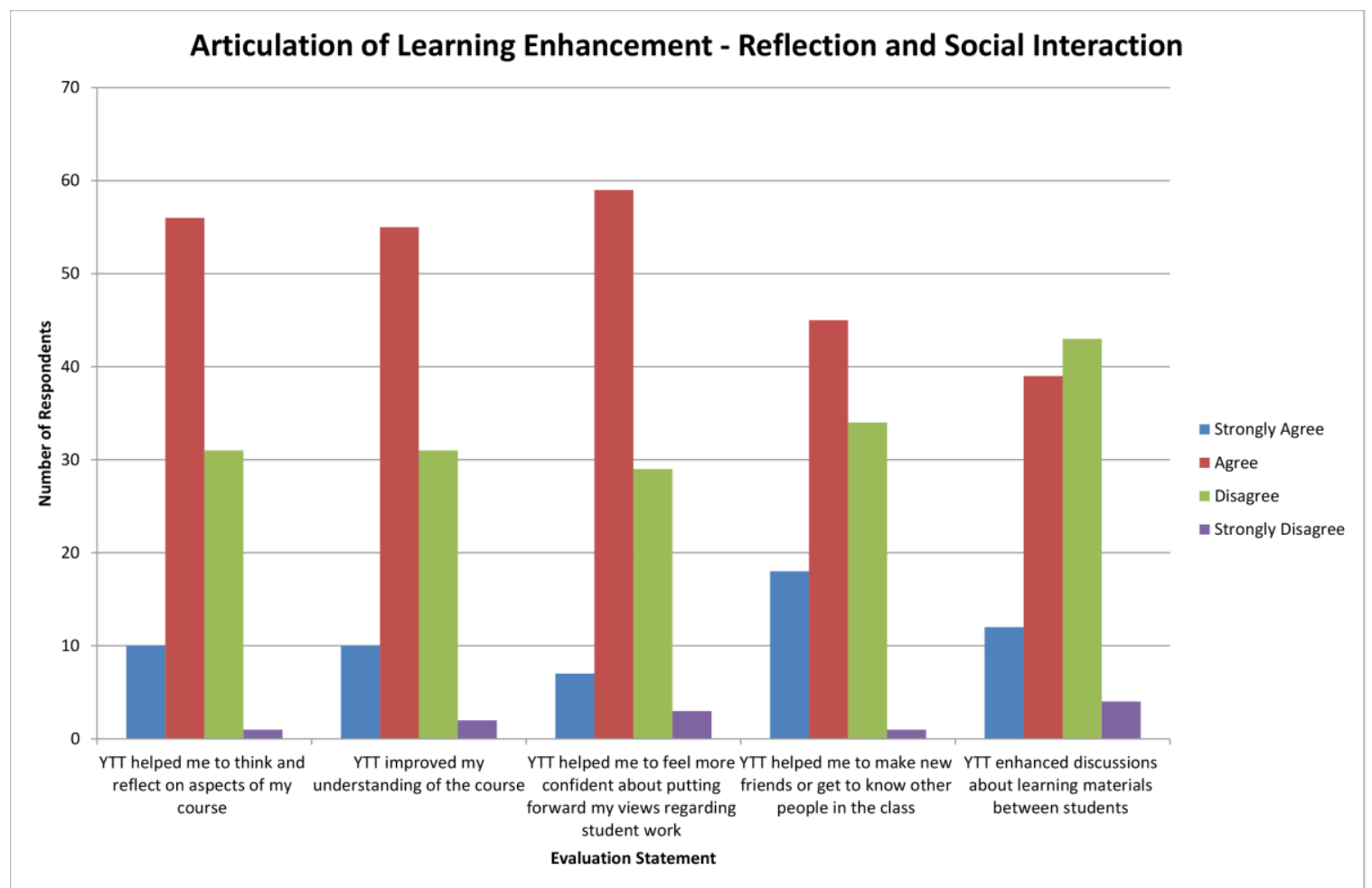

Figure 5. Student responses to reflection and social interaction aspects of the YouTestTube.com project. Total number of respondents $=98 ; 2012 / 13$ academic year.

In a free-response section of the questionnaire students were asked to provide comments on what they considered to be the positive and negative aspects of the YouTestTube experience. Some representative comments are provided below:

\section{Positive:}

"A very different aspect of presenting work."

"Being able to watch a video of practicals before completing them - allowed me to be better prepared." 
"Provides a visual example of how to perform a specific experiment."

"Learning how to create, then edit and upload a video, something I would otherwise not know how to do."

\section{Negative:}

"Time consuming"

315 "Nervous about working in front of a camera."

"To get shots for the video was an extra stress during the experiment."

"Not very social - more of a chore than a pleasure."

\section{Post-Project Interviews}

In post evaluation interviews with the module leader, students $(n=3)$ noted that the greatest gains on learning chemistry via YouTestTube was when they had to revisit the practical afterwards and consider how they might "storyboard" the video and explain the practical effectively to colleagues. They commented that the video activity had helped them to get to know colleagues better within the small practical group, rather than the module group per se. One student noted that because social networking was part of the criteria for the activity, they took part because they had to and did not really bond well with others outside the confines of their individual practical group. This accords with the questionnaire data that indicated students did not find YouTestTube helpful in making friends in the module or in having useful conversations about module material. is required during a normal practical session to capture video footage or photographs. 
Some students were using video editing tools for the first time and this presented a challenge.

The process as evaluated in the $2012 / 13$ academic year continues to the present time. However, since the 2014/15 academic year students were given an additional option of submitting short tutorial-type documentaries providing instruction on how to use individual pieces of laboratory equipment or apparatus, or performing calculations such as theoretical yield, instead of the usual video about the entire practical class. This gave students the opportunity to make a short instructional video that may be of use to new students in forthcoming years of the project.

\section{DISCUSSION}

The process of asking students to create, produce and share digital video adds a further dimension to the learning experience not widely employed in the traditional higher educational context. It facilitates reflection by encouraging students to revisit their own and their colleagues' mini-documentaries; however as evidenced in our study students view the process with varying degrees of enthusiasm. We contend that the use of video documentaries are valuable as students are compelled to express their findings and details of an experiment in an engaging manner, having to articulate concepts and practices in a way that can be readily communicated to peers and academic staff. While students see this as a time consuming task, it adds value to their early tertiary education experience by providing new skills and an opportunity for teamwork. Our findings agree with work by Litchfield et al that involving students in the production of digital video learning resources enhances experience in peer learning, teamwork and communication, understanding and skills ${ }^{25}$. 
In our study many students were happy to avail of the benefits afforded by viewing videos of practical experiments made by colleagues in previous years, and thereby having a preview of the practical to be undertaken. While there was a level of reluctance on the part of some to make a video, others reported that meeting as a small group to edit and produce the final video was where the main learning gains were achieved. In this setting they had to decide on a format and storyboard for the video and this helped with the process of communicating findings in a clear and coherent manner.

Social networking on the YouTestTube site (making friends, rating and commenting on videos) was part of the assessed criteria but students commented that they took part in this aspect only because they were asked to; social networking on YouTestTube.com did not happen organically and certainly did not continue when the module ended. Students see social networking sites such as Facebook as their "social space" and as reported by Madge et al they consider such sites should be used primarily for social reasons and not for formal teaching purposes ${ }^{26}$. We have shown that by developing a platform quite separate from the accepted Facebook and Twitter sites, students were uneasy about posting negative comments on their colleagues' work and therefore most comments were social and encouraging in nature. That said, the YouTestTube site has now grown into a large repository of student-generated videos 375 that demonstrate the utility of social media to support and enhance the learning experience, even if social networking does not flourish there naturally.

\section{CONCLUSION}

Whilst one of the themes of the project was to promote reflection around laboratory experience, only a small number of students cited this as a skill learnt within the module. Additionally, the social networking aspect was not perceived as useful by 
many of the students in helping them to "make friends". It was however realized that the project has many positive attributes such as social function at the micro-group level, engaged learning and use of reflective practice to both inform current understanding and future work. The project also provided students with an opportunity to develop their digital skills in creating and sharing video learning materials that could be of benefit to future students on their course of study. This in turn enhanced their experience of communicating scientific findings through social media.

A limitation of the project is that students self-reported their learning gains from using YouTestTube. Therefore a more rigorous study of learning gain due to this activity could be a focus for the future, but is beyond the scope of the present study.

\section{Sustainability and Transferability}

Our practice has been fully embedded into the practical classes for the introductory chemistry module and the process ran successfully for the academic years 2008/09 until the present (2015/16). Resource costs initially centered on the procurement of cameras and the configuration of the web server used to host videos, however with the infrastructure in place the project operates efficiently from year to year. Costs associated with webservers may be avoided by using online video sharing sites such as YouTube, so long as all local regulations with regard to posting student material on third-party websites are adhered to.

While we retain a small stock of cameras, increasingly students have opted to use their own cameras or phones to capture video or still images. This has therefore reduced the resource implication for the project significantly. With mobile devices now ubiquitous within the student body in academia, user-owned devices represent a great 
potential in utilizing technology for learning ${ }^{27-28}$. Additionally, students are generally au fait with their own mobile device and therefore do not require further training.

While the YouTestTube project was initially piloted in a science setting, the process could be readily transferred to other disciplines. Video sharing on social media sites provides a collaborative environment which engenders peer learning and the

410 sharing of resources. It could be effectively used in distance learning courses, for example, or for students on placement and the social network function could allow for peer assessment of presentations or debates.

\section{ACCESS TO RESOURCES}

While the YouTestTube.com site is closed to outside access, interested practitioners who wish to view a "demo" area of the site with representative video content should email the corresponding author (s.mcclean@ulster.ac.uk) from their institutional email account, with a request to access. The authors reserve the right to withdraw this offer at any time.

\section{ASSOCIATED CONTENT} interested practitioners. (File: FAQ-Questions-About-Video.pdf)

\section{AUTHOR INFORMATION}

Corresponding Author

*E-mail: s.mcclean@ulster.ac.uk

\section{ACKNOWLEDGEMENTS}

This project was funded initially by a STAR Fellowship from Ulster University and by the JISC TechDiS HEAT3 scheme. Additional support was provided by the School of Biomedical Sciences at Ulster University. We gratefully acknowledge the support of Computing Officer Olivier Riché for website configuration and Sharon 
Nigel McDowell for photography used in the abstract graphic.

\section{REFERENCES}

- 1. Jones, T.; Cuthrell, K. YouTube: Educational Potentials and Pitfalls. Computers in the Schools 2011, 28, 75.

- 2. Journal of Visualized Experiments - http://www.jove.com (accessed Jul 2016).

- 3. DNATube - http://www.dnatube.com (accessed Jul 2016).

- 4. Choi, H. J.; Johnson, S. D. The Effect of Context-Based Video Instruction on Learning and Motivation in Online Courses. American Journal of Distance Education 2005, 19 , 215.

- 5. Jonassen, D. H.; Peck, K. L.; Wilson, B. G. Learning with Technology: A Constructivist Perspective; Prentice Hall.: Upper Saddle River, New Jersey, USA, 1999.

- 6. Hilton, G. Rehearsing for an audience: students learning science through video production. International Journal of Innovation and Learning 2011, 9, 311-324.

- 7. Wright, G. A. Improving Teacher Performance using an Enhanced Digital Video Reflection Technique; Springer: New York; 233 Spring Street, New York, NY 10013, United States, 2010.

- 8. O'Donoghue, M.; Cochrane, T. A. The role of live video capture production in the development of student communication skills. Learn. Media Technol. 2010, 35, 323-335.

- 9. Berk, R. A. Multimedia Teaching with Video Clips: TV, Movies, YouTube, and mtvU in the College Classroom. International Journal of Technology in Teaching and Learning 2009, 5, 1-21.

- 9. Skiba, D. J. Nursing Education 2.0: YouTubeTM. Nursing Education Perspectives 2007, 28, 100-102.

- $\quad$ 10. Agazio, J.; Buckley, K. M. An Untapped Resource: Using YouTube in Nursing Education. Nurse Educ. 2009, 34, 23-28 10.1097/01.NNE.0000343403.13234.a2.

- $\quad$ 11. Jung, I.; Lee, Y. YouTube acceptance by university educators and students: a crosscultural perspective. Innovations in Education and Teaching International 2015, 52, 243253.

- $\quad$ 12. Smith, D. K. iTube, YouTube, WeTube: Social Media Videos in Chemistry Education and Outreach. J. Chem. Educ. 2014 91, 1594-1599

- 13. Ryan, B. A Walk Down the Red Carpet: Students As Producers of Digital Video-based Knowledge. Int.J.Technol.Enhanc.Learn. 2013, 5, 24-41. 
- $\quad$ 14. Willmott, C. J. R. Teaching Bioethics via the Production of Student-generated Videos. J. Biol. Educ. 2015, 49, 127-138.

- $\quad$ 15. Vidiscript - http://www.vidiscript.co.uk (not available Jul 2016)

- 16. phpMotion - http://www.phpMotion.com (accessed Jul 2016)

- $\quad$ 17. Kaltura - http://www.kaltura.com (accessed Jul 2016)

- $\quad$ 18. McClean, S.; Hagan, W. P.; Ruddick, J. D.; Adams, K. R. Supporting First-Year Chemistry for Students of Bioscience. In Supporting Students Though Course Design; Rushton, B. S., Cook, A., Macintosh, K. A., Eds.; University of Ulster: Coleraine, Co Londonderry, UK, 2006; pp 83-97.

- 19. Adams, D. Current Trends in Laboratory Class Teaching in University Bioscience Programmes. Bioscience Education e-Journal 2009, 13.

- 20. Collis, M.; Gibson, A.; Hughes, I. E.; Sayers, G.; Todd, M. Report: The Student View of $1^{\text {st }}$ Year Laboratory Work in Biosciences. 2007, UK Centre for Bioscience, Higher Education Academy, UK - https://www.heacademy.ac.uk/sites/default/files/key-skillsstudent-view-1-year.pdf (accessed Jul 2016).

- 21. Collis, M.; Gibson, A.; Hughes, I. E.; Sayers, G.; Todd, M. The Student View of 1st year Laboratory Work in the Biosciences - Score Gamma? Bioscience Education e-Journal 2008, 11-2.

- 22. Wilson, J. 1st Year Practicals: Their Role in Developing Future Bioscientists. 2008, Higher Education Academy UK Centre for Bioscience.

- 23. McClean, S.; Hagan, W. P. YouTestTube.com': using user-generated video to engage students. Perspectives on Pedagogy and Practice 2010, 1, 33-39.

- 24. Windows Live Movie Maker - https://support.microsoft.com/enus/help/18614/windows-essentials (accessed Jul 2016)

- 25. Litchfield, A.; Dyson, L. E.; Wright, M.; Pradhan, S.; Courtille, B. Student-Produced Vodcasts as Active Metacognitive Learning. Proceedings of the 1Oth IEEE International Conference on Advanced Learning Technologies 2010, 560-564.

- 26. Madge, C.; Meek, J.; Wellens, J.; Hooley, T. Facebook, social integration and informal learning at university: 'It is more for socialising and talking to friends about work than for actually doing work'. Learning, Media and Technology 2009, 34, 141-155.

- $\quad$ 27. Andrews, T.; Smyth, R.; Caladine, R. Utilizing Students' Own Mobile Devices and Rich Media: Two Case Studies from the Health Sciences. From 2010 Second International Conference on Mobile, Hybrid, and On-Line Learning, 2010; pp 71-76.

- 28. Davis, S. Observations in classrooms using a network of handheld devices. J. Comput. Assisted Learn. 2003, 19, 298-307. 